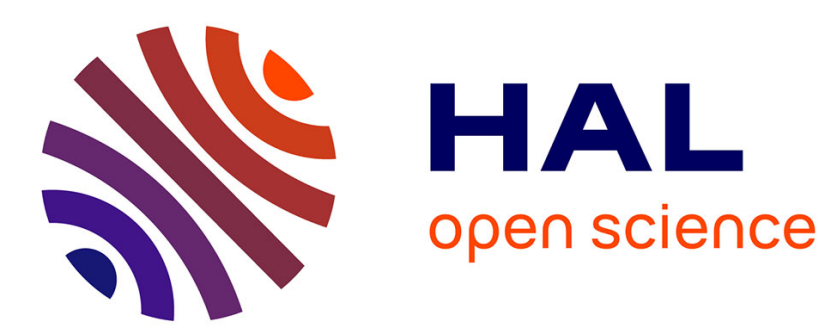

\title{
There is something out there: distal attribution in sensory substitution, twenty years later.
} Malika Auvray, Sylvain Hanneton, Charles Lenay, Kevin O'Regan

\section{To cite this version:}

Malika Auvray, Sylvain Hanneton, Charles Lenay, Kevin O'Regan. There is something out there: distal attribution in sensory substitution, twenty years later.. Journal of Integrative Neuroscience, 2005, 4 (4), pp.505-21. hal-00173591v2

\section{HAL Id: hal-00173591 \\ https://hal.science/hal-00173591v2}

Submitted on 16 Oct 2008

HAL is a multi-disciplinary open access archive for the deposit and dissemination of scientific research documents, whether they are published or not. The documents may come from teaching and research institutions in France or abroad, or from public or private research centers.
L'archive ouverte pluridisciplinaire HAL, est destinée au dépôt et à la diffusion de documents scientifiques de niveau recherche, publiés ou non, émanant des établissements d'enseignement et de recherche français ou étrangers, des laboratoires publics ou privés. 


\section{There is something out there:}

\section{Distal attribution in sensory substitution, twenty years later}

\section{Malika Auvray ${ }^{1}$, Sylvain Hanneton ${ }^{2}$, Charles Lenay ${ }^{3}$ and Kevin O'Regan ${ }^{4}$}

${ }^{1}$ Laboratoire de Psychologie Expérimentale, CNRS UMR 8581, Université Paris 5 René Descartes, 71 Avenue Edouard Vaillant, 92774 Boulogne-Billancourt, France.

${ }^{2}$ Laboratoire Neurophysique et Physiologie du Système Moteur, CNRS UMR 8119 \& UFR STAPS, Université Paris 5 René Descartes, UFR Biomédicale des Saints Pères. 45 rue des Saints Pères. 75270 Paris CEDEX 06 France.

${ }^{3}$ COSTECH, Université de Technologie de Compiègne, Centre Benjamin Franklin, BP 60203 Compiègne, France

${ }^{4}$ Laboratoire de Psychologie Expérimentale, CNRS UMR 8581, Université Paris 5 René Descartes, 71 Avenue Edouard Vaillant, 92774 Boulogne-Billancourt, France.

\section{Corresponding author: Malika Auvray}

Address: Laboratoire de Psychologie Expérimentale,

71 Avenue Edouard Vaillant - 92774 Boulogne-Billancourt, France

Tel: 0033660481444 - Fax: 0033155205854

e-mail: malika.auvray@univ-paris5.fr. Web: http://www.malika-auvray.com 


\begin{abstract}
Sensory substitution constitutes an interesting domain of study to consider the philosopher's classical question of distal attribution: how we can distinguish between a sensation and the perception of an object that causes this sensation. We tested the hypothesis that distal attribution is constituted of three distinct components: the existence of a coupling between subjects' movements and stimulation, the presence of an object and the existence of a perceptual space. We propose to try to understand and systemize the different conditions that are necessary for a distal attribution to occur.
\end{abstract}

We equipped sixty naïve and uninformed participants with a visual-to-auditory substitution device, without any information about it. This device converts the video stream produced by a headmounted camera into a sound stream. We investigated several experimental conditions: the existence or not of a correlation between movements and resulting stimulation, the direct or indirect (with a handle) manipulation of an object, and the presence of a background environment. Participants were asked to describe their impressions by rating their experiences in terms of seven possible "scenarios". These scenarios were carefully chosen to distinguish the degree to which the participants attributed their sensations to a distal cause. Participants rated the scenarios both before and after they were given the possibility to interrupt the stimulation with an obstacle. Did participants extract laws of covariation between their movements and resulting stimulation? Did they deduce the existence of a perceptual space originating from this coupling? Did they individuate objects that caused the sensations? The results showed that, whatever the experimental conditions, participants were able to establish that there was a link between their movements and the resulting auditory stimulation. Detection of the existence of a coupling was more frequent than the inferences of distal space and object.

Key words: Sensory substitution, distal attribution, space, object, objecthood, sensory-motor theory, sensory-motor coupling 


\section{1- Introduction}

Distal attribution can be defined as the ability to attribute the cause of our proximal sensory stimulation to an exterior and distinct object. The question of distal attribution is widely studied in philosophy, but it has not been extensively addressed in experimental psychology. Sensory substitution systems give us the opportunity to study this question. These systems allow information coming from an artificial receptor to be processed by a sensory organ which is unusual for this information source. Sensory substitution systems for example allow visual stimulation to be converted in such a way that it can be processed by the auditory or somaesthetic systems. This perceptual coupling is new for subjects and it provides a way to study how users can integrate and achieve the mastery of a new perceptual space and how they can attain the notion of the existence of an exterior and distant object in this new perceptual space.

Several studies have shown that after training, proximal stimulation produced by sensory substitution devices can be attributed to exterior and distant causes. For instance, with the Tactile Vision Substitution System (TVSS) developed by Bach-y-Rita, users no longer feel the stimulation on their skin where it occurs but directly attribute the cause of the stimulation to a distant object (Bach-y-Rita, 1972, White et al, 1970). Similar observations have been made with visual-to-auditory substitution devices, for instance with the device The Voice developed by Meijer (Meijer, 1992). One user relates that at the beginning she just heard sounds without attributing any meaning to them (as proximal stimulation). However, after training, she was able to distinguish sounds represented by the device from other sounds, and via these sounds she perceived objects as located in a three dimensional space (as distal 
perception). We underline that these observations can be made with many technical devices. For example, a blind person using a cane experiences the stimulation at the end of the cane rather than in the hand, where it occurs.

However, in all these experiments users are generally informed about the functioning of the device and extensively trained to use it. Furthermore, the localization or recognition tasks that have been used presuppose the existence of a distant object. Users therefore know that a distant object can be the cause of the variations in sensation. The following question arises: can distal attribution occur when observers do not have any prior knowledge of the link between their actions with the device and the resulting variation in stimulation? To answer this question, Epstein, Hughes, Schneider and Bach-y-Rita (1986) equipped naïve blindfolded participants with a visual-to-tactile substitution device. The patterns of stimulation that participants received were created by converting a video image obtained from a headmounted camera into vibratory stimulation delivered on one finger (a modified Optacon). However, no information about the functioning of the device was provided to the participants. They were only told that stimulation would be delivered by a device new to them. Results were based on subjective reports of participants' experiences, in which they rated the feasibility of different scenarios describing hypotheses corresponding to the experimental situation they experienced. Results showed that, even if participants become aware of the link between their movements and variations of vibratory stimulation, they never develop the hypothesis of distal attribution.

However, results obtained in the Epstein et al. experiments have to be considered carefully. Each scenario they used proposed a different hypothetical device that the participant 
might be being stimulated through, and participants had to rate the different scenarios as a function of their probability. The authors considered that only one of the proposed scenarios (the one corresponding to the real experimental setup) corresponded to the participant achieving distal attribution. Closer consideration of the scenarios used by Epstein et al. however suggests that in fact each of the scenarios may actually have involved different forms of distal attribution, in some degree.

Thus it could be the case that distal attribution should not be considered as an all-ornone process, but constituted of three distinct components. The first proposed component consists in the subject's realizing that there is a coupling between his movements and incoming stimulation. The second component is the realization of the presence of an outside object. The stimulation obtained is attributed to an exterior and distant cause and this cause is individuated as an object. The third proposed component consists in the existence of a perceptual space. Subjects understand variations in the stimulation as corresponding to spatial variations related to the relative spatial position of the source. Extraction of all these three notions would, we suggest, allow subjects to reach complete distal attribution.

\section{2- Experimental Protocol}

\section{Apparatus}

The visual-to-auditory substitution system used in the present study is the Vibe device, developed in collaboration with the Laboratoire de Neurophysique et Physiologie, CNRS UMR 8119 (Sylvain Hanneton) and the Laboratoire de Psychologie Expérimentale, CNRS UMR 8581 (Malika Auvray, Sylvain Haupert, J. Kevin O’Regan). The Vibe device is an experimental system for the conversion of images into sound patterns. The sound used is 
composed of sinusoidal sounds produced by virtual "sources" corresponding each to a "receptive field" in the image. Each receptive field is a set of localised pixels. The sound's loudness is determined by the mean luminosity of the pixels of the corresponding receptive field. The frequency and the inter-aural disparity are determined by the centre of gravity of the co-ordinates of the receptive field's pixels in the image (see Fig. 1). In the following experiments, we used a virtual "retina" composed of 200 sound sources (i.e. 200 receptive fields of 10 pixels).

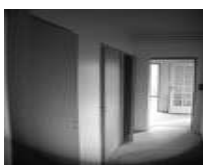

Picture captured by the webcam

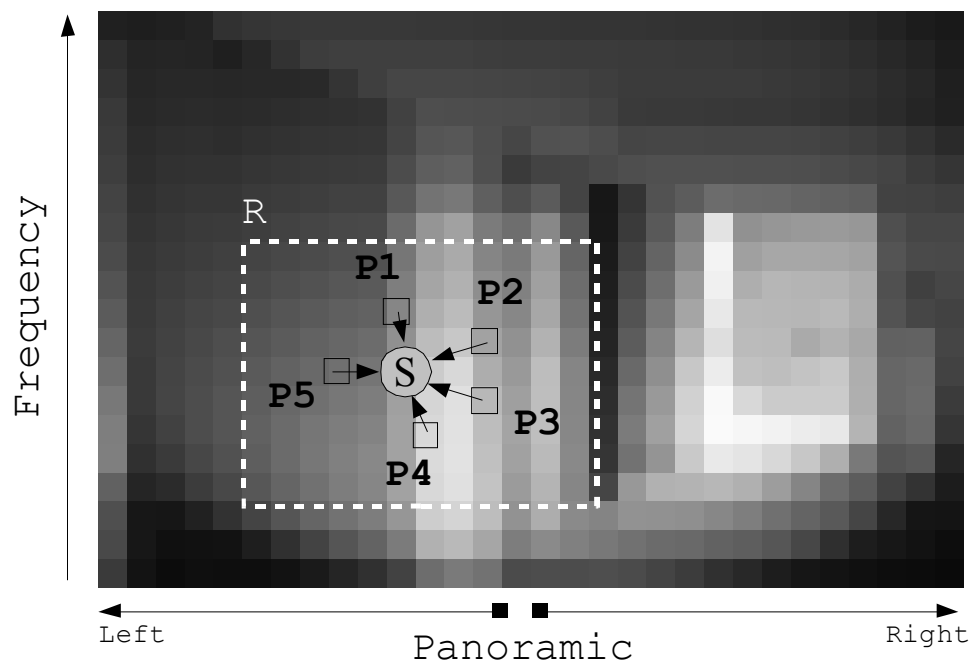

Vibe video-to-sound conversion : sounds produced by the device are originating from $\mathrm{n}$ sinusoidal sources. The amplitude of the sound produced by each source is updated each time a picture is captured by the webcam. This update depends on the state of the «receptive field $»$ linked to the source. A receptive field is a set of $\mathrm{k}$ pixels. The amplitude of the sound produced by one source is computed from the mean value of the RGB components (brightness) over the k pixels of the receptive field. The position associated to the source in the picture is the barycenter of the position of the k pixels. The frequency of the sound is given by the vertical position of the source. The balance of the sound between the left and right channels (panoramic) is given by the horizontal position of the source. A threshold can be applied in order to make sounds produced by either dark or luminous objects in the picture more prominent. A receptive field (R) made of five pixels (P1 to P5) and controlling the sound emitted by a source (S) is figured on this illustration.

Figure 1. Schema of the visual-to-auditory substitution device Vibe

\section{Participants}

Sixty participants were recruited in the student population of Paris 5 University. All participants were naïve as to the purpose of the study and none of them had previous experience with a sensory substitution device. The participants received neither 
money nor course credit for their participation. The experiment took on average one hour to be completed.

\section{Procedure}

The experiments were done in a dark room. Participants were blindfolded prior to entering the room. Before entering the room they were simply told that they would hear sounds new to them and that they would have to rate the plausibility of several explanations concerning these sounds. We gave them no other explanation concerning the experiment or concerning the functioning of the device. Once participants were seated on the room we fitted them with a pair of headphones (Sennheiser H280 pro). A webcam (Qcam 330) was fixed on the top of the headphones in such a way that participants could not detect its presence. This webcam acquired images from the surroundings and was connected to a Sony PCG-FX401 personal computer. The Vibe software hosted in the PC translated, in real time, images captured by the webcam into auditory output transmitted to the participants through the headphones. The room was dark and the participants manipulated a luminous object that differed according to the different experimental conditions (see below).

During the first fifteen minutes, participants were instructed to make a variety of movements so that they would understand the different possible modes of interaction with the device. These movements included movements of the head only, movements of the arm only, movements in opposition of the head and hand, and tracking. Participants were then given five minutes to explore the scene freely. At the end of the exploration, participants were asked to score each of seven possible explanations on a discrete scale from zero (not plausible) to ten (certainty), as a function of their estimation of the plausibility of the scenarios. 
In a second part of the experiment which we called the "interruptible source" session, participants were placed in the same experimental conditions. We asked them to carry out the same succession of movements. Then, we asked them to hold a 21 x $29.7 \mathrm{~cm}$ sheet of cardboard in front of their faces and to make vertical movements with it. These movements were done in such a way that the cardboard interrupted auditory stimulation caused by the luminous object. We then asked the participants to score the different scenarios again.

\section{Experimental conditions}

Participants were divided into five groups of 12 participants.

1- One group manipulated a lever with a luminous cube $(14 \times 14 \times 14 \mathrm{~cm})$ fixed on it. The lever could be moved in all directions in the horizontal plane.

2- One group was only allowed to use movements of their body (displacement of the camera) in order to perceive a luminous cube $(14 \times 14 \times 14 \mathrm{~cm})$ placed on a table in front of them.

3- One group manipulated a lever with a luminous object fixed on it, as in condition 1. However, additionally, a background environment consisting of six small light emitting diodes fixed on the wall was present.

4- One group directly manipulated a luminous object: a luminescent juggling ball having a diameter of $7 \mathrm{~cm}$ diameter (see Fig. 2).

5- One control group was divided into two groups of six participants. Participants were placed in the same experimental conditions as in the first and second conditions. Participants of the control group heard sounds that did not correspond to their movements. Sounds had been prerecorded from previous participants placed in the corresponding experimental conditions 1 and 2. 


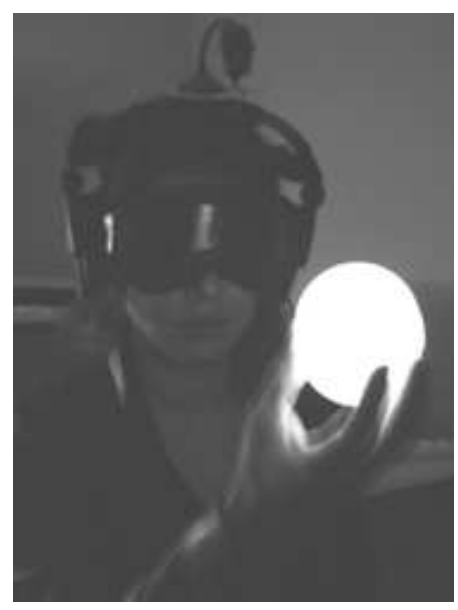

Figure 2. Picture of the luminescent ball used in the experimental condition 4

\section{Scenarios}

Scenarios were written in order to determine if participants had inferred the different components of distal attribution that we have proposed: existence of a coupling between sensory input and movements (C), existence of an object, source of the sensations (O), existence of the notion of space achieved via the coupling (S).

The notion of object $(\mathrm{O})$ is assumed to imply the fact that the observer considers the source of stimulation to be constituted by an externally localizable object. However in this (primitive) notion of object, the spatial localization of the object may not be specified in relation to other possible spatial localizations. On the other hand, when the observer perceives the spatial localisation of the object as being potentially modifiable and organizable into a coherent (presumably approximately euclidean) space, then we consider that the observer additionally possesses the notion of space $(\mathrm{S})$.

In defining our scenarios, our purpose was to attempt to test for the presence of all possible combinations of the notions of coupling (C), object (O) and space (S). Some combinations were impossible however, for example having $\mathrm{S}$ but not $\mathrm{O}$ (since we defined $\mathrm{S}$ 
as the space of possible relative position of $\mathrm{O}$ ). The scenarios were slightly modified for experimental conditions 2 and 4 (see Appendix I).

1- A luminous object is fixed on the end of the handle that I manipulate. An optical device located on my head films this luminous object and converts images of this object into a pattern of sounds $(\boldsymbol{C}, \boldsymbol{O}, \boldsymbol{S})$. (This is the scenario corresponding to the real experimental situation, that is sensory substitution).

2- Sensors located on my head and my hand record movements of my head and my hand. These movements create displacements of myself in front of an object in virtual reality. Images of this object are converted into pattern of sounds $(\boldsymbol{C}, \boldsymbol{O}, \boldsymbol{S}$ as in a simulated environment).

3- Movements of my head and my hand control the sounds of a musical instrument $(\boldsymbol{C}, \boldsymbol{O}$, $7 S)$.

4- Sensors located on my head and my hand record movements of my head and my hand. Positions of my head and my hand are directly converted into a pattern of sounds $\left.(\boldsymbol{C},\urcorner_{\urcorner} \boldsymbol{O},\right\urcorner$ S).

5- The experimenter controls sound variations as a function of the movements of my head and my hand $\left(C,{ }_{\urcorner} \boldsymbol{O},{ }_{\urcorner} S\right)$.

6- An object situated in front of me emits sounds that are not linked to my own movements. These sounds are transmitted to my ears $\left.\left({ }_{\urcorner} C, O,\right\urcorner_{7}\right)$.

7- The device is pre-programmed via a computer to produce sounds randomly, not linked to the position of my body or to my movements $\left({ }_{\urcorner} \mathrm{C},{ }_{\urcorner} \mathrm{O},{ }_{\urcorner} \mathrm{S}\right)$.

\section{3- Results}




\section{3-1- Scoring of the scenarios}

\section{a) Global contribution of the experimental factors}

In the experimental design there was one between-group factor: the experimental condition (EC) and two repeated measures factors: the seven level "scenario" factor (SC) and the two level "session" factor (SE). A preliminary analysis of variance concerning the effects of these factors on the "score" (S) dependent variable showed a significant effect of the factor $\mathrm{SC}(\mathrm{F}(6,324=9,08 ; \mathrm{p}<0,0001)$; a significant interaction between the factor SC and the factor $\mathrm{EC}(\mathrm{F}(30,324)=11,625 ; \mathrm{p}<0,0001)$; and a significant interaction between the factor $\mathrm{EC}$ and the factor $\mathrm{SE}(\mathrm{F}(6,324)=3,3 ; \mathrm{p}<0,004)$. These preliminary analyses showed that participants attributed different scores to the different scenarios. But these scores depended both on the experimental condition and on the experimental session.

\section{b) First session}

Participants belonging to the groups 1 - lever -, 2 - distant object -, 3 - lever and background - and 4 - object - gave a better score $(5.3 \pm 2.8)$ to the scenarios 1 to 5 that involve a link between participants' movements and the resulting stimulation, than to the scenarios $\mathrm{N}^{\circ} 6$ and $\mathrm{N}^{\circ} 7(1.4 \pm 2.6)$ that involve a random relationship between movements and stimulation (see table I). Participants belonging to the two control conditions provided opposite scores. The first five scenarios obtained a weaker score $(2.3 \pm 0.9)$ than the two last scenarios $(6.7 \pm 1.6)$. 


\begin{tabular}{|c|c|c|c|c|c|c|c|c|c|c|c|c|c|c|c|c|c|c|}
\hline \multirow{2}{*}{ Experimental conditions } & \multicolumn{2}{|c|}{$\begin{array}{l}\text { 1- sensory } \\
\text { substitution }\end{array}$} & \multicolumn{2}{|c|}{$\begin{array}{l}\text { 2- Virtual } \\
\text { Reality }\end{array}$} & \multicolumn{2}{|c|}{$\begin{array}{l}\text { 3- Musical } \\
\text { instrument }\end{array}$} & \multicolumn{2}{|c|}{ 4- sensors } & \multicolumn{2}{|c|}{$\begin{array}{l}\text { 5- Experi- } \\
\text { menter }\end{array}$} & \multicolumn{2}{|c|}{$\begin{array}{l}\text { 6-random } \\
\text { object }\end{array}$} & \multicolumn{2}{|c|}{$\begin{array}{l}\text { 7- Random } \\
\text { program }\end{array}$} & \multicolumn{2}{|c|}{$\begin{array}{l}\text { Scenarios } 1 \\
\text { to } 5\end{array}$} & \multicolumn{2}{|c|}{$\begin{array}{l}\text { Scenarios } 6 \\
\text { to } 7\end{array}$} \\
\hline & \multicolumn{2}{|c|}{ Mean \pm SD } & \multicolumn{2}{|c|}{ Mean \pm SD } & \multicolumn{2}{|c|}{ Mean \pm SD } & \multicolumn{2}{|c|}{ Mean \pm SD } & \multicolumn{2}{|c|}{ Mean \pm SD } & \multicolumn{2}{|c|}{ Mean \pm SD } & \multicolumn{2}{|c|}{ Mean \pm SD } & \multicolumn{2}{|c|}{ Mean \pm SD } & \multicolumn{2}{|c|}{ Mean \pm SD } \\
\hline \multirow{2}{*}{ 1- Lever } & 4.4 & \pm 3.1 & 5.4 & \pm 2 & 6.2 & \pm 3.5 & 7 & \pm 2.5 & 4.1 & \pm 2.8 & 2 & \pm 2.7 & 1.7 & \pm 2.7 & 5.4 & \pm 2.9 & 1.8 & \pm 2.6 \\
\hline & 7.6 & \pm 2.7 & 5.8 & \pm 3.3 & 5.2 & \pm 2.8 & 6.5 & \pm 2.7 & 4.2 & \pm 2.4 & 0.8 & \pm 1.6 & 1.1 & \pm 1.6 & 5.8 & \pm 2.9 & 0.6 & \pm 1.5 \\
\hline \multirow{2}{*}{ 2- Distant object } & 5.4 & \pm 2.6 & 5.3 & \pm 2.7 & 4.9 & \pm 2.4 & 6.4 & \pm 2.4 & 6.1 & \pm 3.4 & 0.7 & \pm 0.8 & 1.3 & \pm 2.6 & 5.6 & \pm 2.7 & 1 & \pm 1.9 \\
\hline & 7.8 & \pm 2.2 & 4.7 & \pm 3.7 & 3.5 & \pm 2.9 & 3.7 & \pm 2.8 & 2.8 & \pm 2.9 & 0.8 & \pm 1.3 & 1 & \pm 2 & 4.5 & \pm 3.3 & 0.9 & \pm 1.7 \\
\hline \multirow{2}{*}{ 3- Lever + back-ground } & 4.7 & \pm 3 & 4.7 & \pm 2.7 & 5 & \pm 2.3 & 5.2 & \pm 2.7 & 3.9 & \pm 3.3 & 2.2 & \pm 2.7 & 2.7 & \pm 2.7 & 4.7 & \pm 2.7 & 2.5 & \pm 2.8 \\
\hline & 6.2 & \pm 3.4 & 4.6 & \pm 3.1 & 5.5 & \pm 2.9 & 5.7 & \pm 2.1 & 3.3 & \pm 2.7 & 1.4 & \pm 2.1 & 1.8 & \pm 2.6 & 5 & \pm 3 & 1.6 & \pm 2.4 \\
\hline \multirow{2}{*}{ 4- Object } & 6.3 & \pm 1 & 5.7 & \pm 2.6 & 7.1 & \pm 2.7 & 7.2 & \pm 2.1 & 1.6 & \pm 1.6 & 0.4 & \pm 0.7 & 0.7 & \pm 1.2 & 5.6 & \pm 3 & 0.5 & \pm 1 \\
\hline & 7.5 & \pm 2.4 & 3.9 & \pm 2.2 & 5.1 & \pm 3.3 & 5.8 & \pm 3.2 & 1.5 & \pm 2.7 & 0.3 & \pm 0.6 & 0.4 & \pm 1.7 & 4.8 & \pm 3.4 & 0.4 & \pm 0.6 \\
\hline \multirow{2}{*}{$\begin{array}{l}\text { 5- control condition } \\
\text { lever }\end{array}$} & 2.3 & \pm 1 & 2.7 & \pm 1.2 & 2 & \pm 0.6 & 3 & \pm 1.3 & 2.2 & \pm 0.5 & 6.2 & \pm 2.8 & 6.8 & \pm 2.5 & 2.4 & \pm 1 & 6.5 & \pm 2.5 \\
\hline & 2 & \pm 0.6 & 2.2 & \pm 1 & 1.5 & \pm 1 & 3 & \pm 0.9 & 3 & \pm 0.6 & 6.7 & \pm 1 & 8.5 & \pm 0.5 & 2.3 & \pm 1 & 7.6 & \pm 1.2 \\
\hline \multirow{2}{*}{$\begin{array}{l}\text { 6- control condition } \\
\text { distant object }\end{array}$} & 2 & \pm 0.9 & 2 & \pm 0.6 & 1.8 & \pm 0.7 & 2.3 & \pm 1 & 3 & \pm 0.9 & 6.5 & \pm 2.1 & 7.2 & \pm 1.2 & 2.2 & \pm 0.9 & 6.8 & \pm 1.6 \\
\hline & 1.8 & \pm 0.4 & 2 & \pm 1.1 & 2.3 & \pm 0.5 & 2.7 & \pm 1 & 3.2 & \pm 0.7 & 6.3 & \pm 2.6 & 8.3 & \pm 0.8 & 2.4 & \pm 0.9 & 7.3 & \pm 2.1 \\
\hline \multirow{2}{*}{ conditions 1 to 4} & 5.2 & \pm 2.7 & 5.3 & \pm 2.5 & 5.8 & \pm 2.8 & 6.5 & \pm 2.5 & 3.9 & \pm 3.2 & 1.3 & \pm 2.1 & 1.6 & \pm 2.4 & 5.3 & \pm 2.9 & 1.5 & \pm 2.3 \\
\hline & 7.3 & \pm 2.7 & 4.7 & \pm 3.1 & 4.8 & \pm 3 & 5.4 & \pm 2.8 & 3 & \pm 2.8 & 0.8 & \pm 1.5 & 1.1 & \pm 1.8 & 5 & \pm 3.2 & 1 & \pm 1.7 \\
\hline \multirow{2}{*}{ Conditions $5 \& 6$} & 2.2 & \pm 0.3 & 2.3 & \pm 1 & 1.9 & \pm 0.7 & 2.7 & \pm 1.1 & 2.6 & \pm 0.9 & 6.3 & \pm 2.3 & 7 & \pm 1.9 & 2.3 & \pm 0.9 & 6.7 & \pm 1.6 \\
\hline & 1.9 & \pm 0.5 & 2.1 & \pm 1 & 1.9 & \pm 0.9 & 2.8 & \pm 0.9 & 3.1 & \pm 7 & 6.5 & \pm 1.9 & 8.4 & \pm 0.7 & 2.4 & \pm 0.9 & 7.7 & \pm 2.1 \\
\hline
\end{tabular}

Table I. Means of the scores attributed to each scenario during the first session (in white) and during the second session (in grey). The means are taken over all participants.

The first scenario, corresponding to the real experimental set up, was never the best rated. We averaged the scores over all the experimental conditions, except for the two control conditions. The results are as follow: the scenario $\mathrm{N}^{\circ} 4-$ sensors - had the best score $(6.4 \pm$ 2.5). Then comes the scenarios $\mathrm{N}^{\circ} 3$ - musical instrument $-(5.8 \pm 2.9), \mathrm{N}^{\circ} 2-$ virtual reality $(5.3 \pm 2.5), \mathrm{N}^{\circ} 1-$ sensory substitution $-(5.2 \pm 2.7)$ and $\mathrm{N}^{\circ} 5$ - experimenter $-(3.9 \pm 3.2)$. The two last scenarios, $\mathrm{N}^{\circ} 7$ - random program $-(1.6 \pm 2.5)$ and $\mathrm{N}^{\circ} 6$ - random object $-(1.3 \pm 2.1)$ got weaker scores.

If we consider the effect of the experimental conditions on the score of the first scenario, condition 4 in which participants manipulated an object directly slightly improved their score $(6.3 \pm 2)$. Scenario $\mathrm{N}^{\circ} 1$ in condition 2 - distant object - obtained better scores $(5.4 \pm 2.6)$ than 
the same scenario in condition 1 in which participants manipulated a lever $(4.4 \pm 3.11)$. Condition 3 in which a background environment was present slightly improved participants' performance $(4.7 \pm 3)$. The experimental condition significantly influenced the score of scenario $\mathrm{N}^{\circ} 1(\mathrm{~F}[5,54]=3.7198, \mathrm{p}<0.006)$. However, the mean score of scenario $\mathrm{N}^{\circ} 1$ is significantly different from mean scores of the two control conditions only for the "object" condition (Tukey's post-hoc test, respectively $\mathrm{p}<0.02$ and $\mathrm{p}<0.03$ ).

\section{C) Second session (with interruptible source)}

Manipulation of the cardboard had an effect on participants' scores. It increased the mean score of the first scenario and decreased the mean scores of the others (see Fig. 3). An ANOVA revealed a global effect of the factor $\mathrm{SE}(\mathrm{F}[1,54)]=8.33 ; \mathrm{p}<0.006)$ and of the factor $\mathrm{EC}(\mathrm{F}[5,54]=10.6 ; \mathrm{p}<0.0001)$.

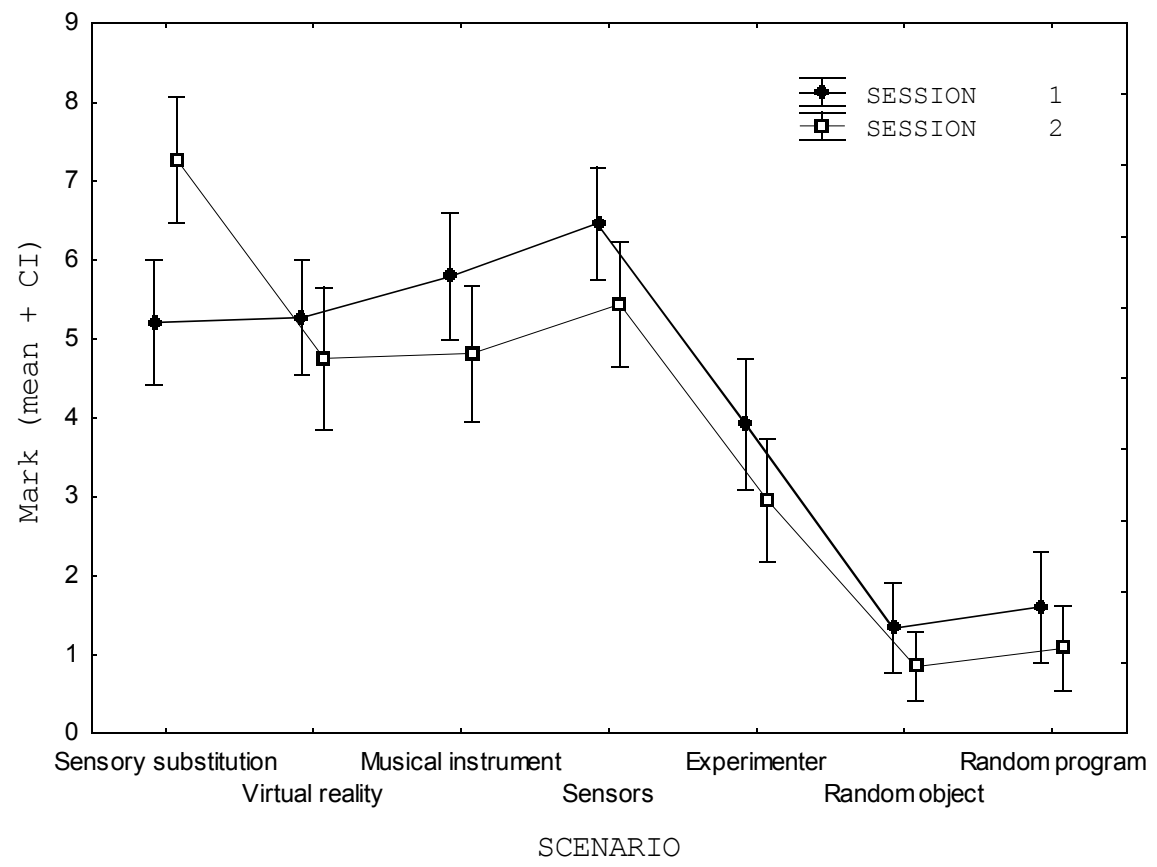

Figure 3. Means over the experimental conditions 1- Lever, 2- Distant object, 3- Lever and background and 4- Object, of the scores attributed to the different scenarios for the first session (filled circles) and the second session (empty boxes). The means are taken over all participants.

The error bars represent $95 \%$ confidence intervals. 
Participants belonging to groups 1 to 4 allocated a higher score $(5 \pm 3.2)$ to scenarios 1 to 5 (that involve a link between their movements and the resulting stimulation) than to the two other scenarios $(1 \pm 1.7)$. Participants belonging to the two control groups provided opposite scores. The first five scenarios got a lower mean score $(2.4 \pm 0.9)$ than the two last scenarios $(7.5 \pm 2.1)($ see Table 1$)$.

The first scenario, corresponding to the real experimental set up was the best rated of all the experimental conditions. We averaged the scores obtained in all the experimental conditions, without including scores obtained in the two control conditions. The results were as follow: scenario $\mathrm{N}^{\circ} 1$ - sensory substitution - gets the highest score $(7.3 \pm 2.7)$. Then came scenario $\mathrm{N}^{\circ} 4-$ sensors $-(5.4 \pm 2.8)$, scenario $\mathrm{N}^{\circ} 3$ - musical instrument $-(4.8 \pm 3)$, scenario $\mathrm{N}^{\circ} 2$ - virtual reality $-(4.7 \pm 3.1), \mathrm{N}^{\circ} 5-$ experimenter $-(3 \pm 2.8)$, scenario $\mathrm{N}^{\circ} 7$ - random program $-(1.1 \pm 1.9)$ and scenario $\mathrm{N}^{\circ} 6$ - random object $-(0.8 \pm 1.5)$.

If we consider the effect of the experimental conditions on the scoring of the first scenario, conditions 4 - object $-(7.5 \pm 2.54), 2$ - distant object $-(7.8 \pm 2.2)$ and 1 - lever $(7.6 \pm 2.7)$ allowed a high score for this scenario. Participants' scoring was lower in condition 3 - lever and background environment $-(6.2 \pm 3.4)$.

\section{3-2- Results as a function of the components of distal attribution}

Each scenario was determined by the combination of three components: the existence of a coupling, the existence of an object, the existence of a space. Separate weights, shown in Table 2, were attributed to these three components $(\mathrm{C}, \mathrm{O}$ and $\mathrm{S})$ in order that the sum of these weights is zero. The weights of the scenarios containing the considered component are 
positive; the weights of the scenarios that do not contain the considered component are negative. The sum of the positive weights is 1 and the sum of the negative weights is -1 . Thus, a participant attributing the same score for each scenario would obtain the result 0 for the three components $\mathrm{C}, \mathrm{O}$ and $\mathrm{S}$. A participant attributing the maximal score to the scenarios containing one component and the minimal score to others would obtain the result 10 (respectively -10 for the inverse score). The value of the $\mathrm{C}, \mathrm{O}$ and $\mathrm{S}$ components estimated through the score of scenarios can vary between -10 and 10 . A positive value means that participants attributed a better note to the scenarios containing the considered component than to others. In the following, we will refer to the weighted mean obtained for a participant for a given component as his "extracted index" for that component, since it indicates to what extent the participant extracted that component of distal attribution.

\begin{tabular}{|l|c|c|c|c|c|c|c|}
\hline $\begin{array}{l}\text { Scenario } \\
\text { Component }\end{array}$ & $\mathbf{1}$ & $\mathbf{2}$ & $\mathbf{3}$ & $\mathbf{4}$ & $\mathbf{5}$ & $\mathbf{6}$ & $\mathbf{7}$ \\
\hline C (coupling) & 0,2 & 0,2 & 0,2 & 0,2 & 0,2 & $-0,5$ & $-0,5$ \\
\hline O (object) & 0,25 & 0,25 & 0,25 & $-0,33$ & $-0,33$ & 0,25 & $-0,33$ \\
\hline S (space) & 0,5 & 0,5 & $-0,2$ & $-0,2$ & $-0,2$ & $-0,2$ & $-0,2$ \\
\hline
\end{tabular}

Table II. Weights attributed to the components $C, O$ and $S$ for each scenario

\section{a) Coupling}

Considering the mean value of the extracted index for component $\mathrm{C}$, participants in experimental conditions 1 to 4 seemed to understand that there was a link between their actions and the resulting stimulation from the first session (source not interruptible) (3.9 \pm 2.7). This is not the case for participants in the two control conditions $(-4.3 \pm 2.5)$. Condition 4 - object - favours most the inference of coupling $(5 \pm 1.2)$, followed by conditions 1 - lever $-(3.6 \pm 3.1), 2-$ distant object $(4.6 \pm 2.1)$, and 3 - lever and background $-(2.2 \pm 3.3)$ (see

Fig. 4). The mean values obtained in the two control conditions were negative and 
significantly different from the values obtained in the other conditions (test post-hoc HSD of Tukey).

Manipulation of the cardboard in the second session did not increase the extracted index obtained for the $\mathrm{C}$ component. It increased, but not significantly, the results obtained in conditions 1 - lever $-(4.9 \pm 2.7)$ and 3 - lever and background - and decreased the results obtained in conditions 4 - object $-(4.4 \pm 2.6)$ and 2 - distant object $-(3.6 \pm 2)$. An ANOVA with factors EC and SE showed that only the factor EC had an influence on the mean value obtained for $\mathrm{C}(\mathrm{F}[5,54]=46.04 ; \mathrm{p}<0.0001)$.

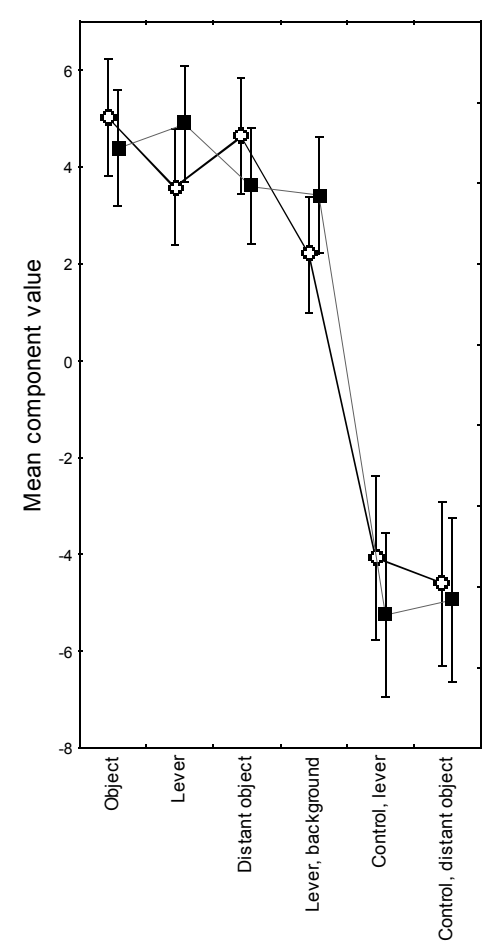

Coupling

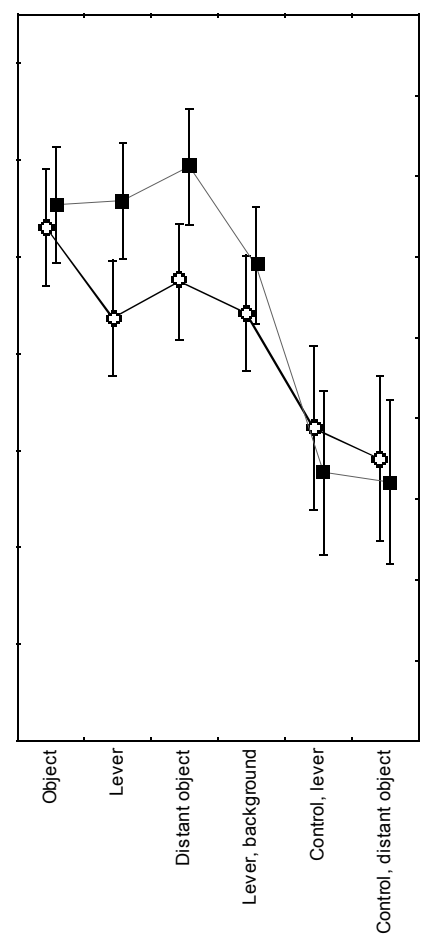

Space

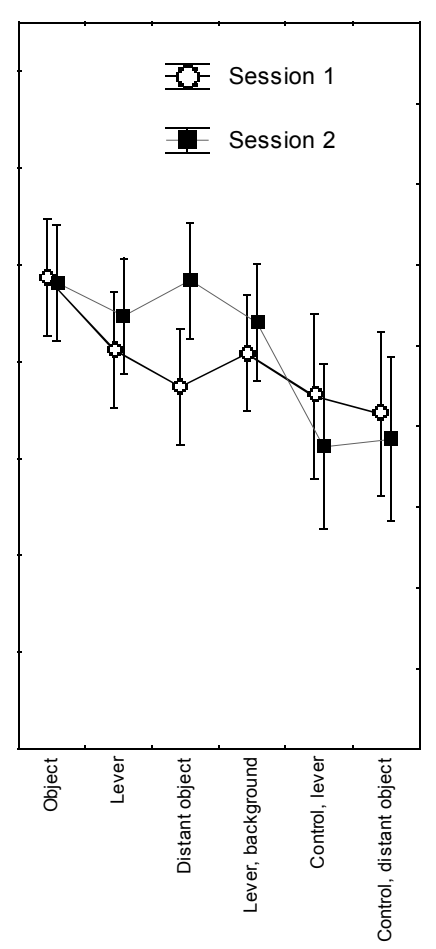

Object

Figure 4. Extracted index for the components coupling, space and object for the first session (empty circles) and the second session (filled boxes). The means are taken over all subjects.

The error bars represent $95 \%$ confidence intervals. 


\section{b) Object}

During the first session (source not interruptible), the inference of the presence of an object reflected by the mean value of the extracted index for the $\mathrm{O}$ component, was not strongly supported. The results were just above the mean for experimental conditions 1 to 4 $(0.4 \pm 2.1)$ and just below the mean for the two control conditions $(-0.9 \pm 0.7)$. An ANOVA revealed an influence of factor $\mathrm{EC}$ on the mean value of the extracted index for the $\mathrm{O}$ component $(\mathrm{F}[5,54]=6.31 ; \mathrm{p}<0.0002)$ and a significant interaction between factors $\mathrm{EC}$ and $\mathrm{SE}(\mathrm{F}[5,54]=2.95 ; \mathrm{p}<0.02)$. Thus, the means obtained for the $\mathrm{O}$ component depended both on the experimental condition and on the session. More precisely, it was only in the experimental condition "distant object" that the mean values obtained for $\mathrm{O}$ were significantly different for the first and the second condition. The second session (with interruptible source) allowed a significant increase of the mean value of the extracted index for the $\mathrm{O}$ component (from $-0.5 \pm 2.4$ to $1.7 \pm 1.6)$ for condition $2-$ distant object $-(\mathrm{p}<0,02$, HSD of Tuckey). The two experimental conditions allowing the highest value for $\mathrm{O}$ at the second session are 4 object $-(1.6 \pm 1.5)$ and $2-$ distant object $-(1.7 \pm 1.6)$.

\section{c) Space}

During the first session, the inference of a space reflected by the value of the extracted index for the $\mathrm{S}$ component obtained positive results for conditions 1 to 4 . The results were stronger for conditions 4 - object $-(2.6 \pm 2.4)$ and condition $2-$ distant object $-(1.5 \pm 2.6)$ than for conditions $1-$ lever $-(0.7 \pm 2.4)$ and $3-$ lever and background $-(0.8 \pm 2.7)$. The two control conditions obtained negative results (-1.9 \pm 1.5$)$ (see Fig. 4). An ANOVA revealed an influence of the factors $\operatorname{EC}(\mathrm{F}(5,54)=12,7 ; \mathrm{p}<0,0001)$ and $\operatorname{SE}(\mathrm{F}(5,54)=2,1 ; \mathrm{p}<0,05)$ on the mean value of $\mathrm{S}$. The interaction between these two factors is not significant. Thus the 
value attributed to the component space is affected by the experimental condition and by the session.

The mean values of the extracted index for the $\mathrm{S}$ component were higher for the second session (interruptible source) $(2.7 \pm 2.4)$ than for the first session $(1.4 \pm 1.6)$. This increase is important essentially for conditions 2 - distant object - (from $1.5 \pm 2.6$ to $3.1 \pm 2.2$ ) and $1-$ lever - (from $0.7 \pm 2.4$ to $3.2 \pm 1.6$ ). But a post-hoc test (HSD of Tukey) does not show any significance of this increase. The results obtained in the two control conditions are weaker at the second $(-2.5 \pm 0.8)$ session than at the first session $(-1.9 \pm 1.5)$.

\section{4- Discussion}

Our experiments aimed to study which components of distal attribution users of a new technical device can attain in the absence of prior knowledge about the causal link between their movements and the resulting sensory stimulation. To test this question, we equipped naïve participants with a visual-to-auditory substitution device without any information about it. Results showed that, in all experimental conditions, participants were able to establish that there is a link between their movements and the resulting auditory stimulation. This perception of a coupling is more frequent than the inferences of space and object. However, the ability to interrupt the stimulation and the direct manipulation of an object significantly favor the emergence of the notions of space and object.

The first main result of our experiments is that participants who are placed in experimental conditions where there is a link between their movements and the resulting auditory stimulation actually infer the existence of a coupling. In this respect a comparison of 
the results obtained in the control conditions and in other conditions seems relevant. Participants placed in the control conditions heard sounds that did not correspond to their movements. They attributed a high score to scenarios $\mathrm{N}^{\circ} 6$ and $\mathrm{N}^{\circ} 7$, implying the idea of sounds emitted randomly, and they attributed a low score to the other scenarios. Participants thus understood that there was no coupling between their movements and the resulting auditory stimulation. Participants placed in the four other conditions provided opposite scores. Thus, in the four main experimental conditions, the low scores attributed to scenarios $\mathrm{N}^{\circ} 6$ and $\mathrm{N}^{\circ} 7$ and the high scores attributed to the others seem to correspond to an effective inference established by participants. From their experience with the device, participants extracted laws of co-variation between their movements and the resulting auditory stimulation. They scored the scenarios as a function of the inferences implied without taking into account other elements contained in the scenarios that would have seemed more probable or credible. The scores obtained from considering each scenario were in accordance with results we obtained by calculating an extracted index for each component based on the ratings that the participant made of all the scenarios. The method proposed to extract an index for the distal attribution components allowed us to obtain a meta-analysis of participants' answers. This method provided an estimation of the degree to which the participant had extracted each of the three components, $\mathrm{C}, \mathrm{O}$ and $\mathrm{S}$, from the situation and thereby established a direct link with our theoretical assumptions.

The mean value of the extracted index measuring the component "coupling" is negative for the two control conditions and is highly positive for the others. However, the mean value of the extracted index for the component "coupling" is lower in conditions 1 (lever) and 3 (lever and background) than in conditions 2 (distant object) and 4 (object). We had initially 
thought that conditions 1 and 3 would help participants because they offer an indirect tactile access to the object or to spatial landmarks. Apparently however, the complexities these conditions induce in the device hinder the extraction of a coupling between participants' movements and the resulting auditory stimulation. Results obtained in the "lever" condition can be better understood by comparing them to those obtained in the "object" condition. The lever restricts the freedom of action of the participants and disturbs the understanding of the situation. When the object is in the hand, participants can easily put the movements they initiate with the object into correspondence with the received sensory stimulation. There is indeed a high compatibility between the spatial information concerning the position of the hand in space (that the participant has access to for example thanks to proprioception) and the spatial information concerning the position of the object. On the other hand, when using the lever, participants have less precise information about the relation between the position of their hand and the position of the object. In condition 3, the added background disturbs even more the comprehension of a coupling. The supposed help provided by the spatial landmarks in the background may not be useful because the complexity of the device has the effect that participants only partially understand the existence of a coupling.

The second main result of our experiments is that the extracted index obtained for the component "coupling" develops prior to the extracted index obtained for the components "object" and "space". Thus, participants placed in experimental conditions 1 (lever), 2 (distant object) and 3 (lever and background) inferred that there was a correlation between their movements and the resulting auditory stimulation. But this inference did not lead immediately to the understanding that the stimulation referred to outside objects and to the comprehension that variations in the stimulation corresponded to spatial variations in relation to this object. 
These results tend to corroborate the hypothesis that the extraction of systematic covariation between self-movements and resulting stimulation allows the development of distal attribution and progressively subserves the acquisition of the concepts of space and object (Piaget, 1936). In other words, "It is only by voluntarily bringing our organs of sense in various relations to the objects that we learn to be sure as to our judgements of the causes of our sensations. We explain the table as having existence independent of our observation because, at any moment we like, simply by assuming the proper position with respect to it, we can observe it" . This necessity of a structured correlation between actions and sensations in order to allow distal attribution was proposed by Condillac (1754). If we just passively received sensations, we would not understand that these sensations refer to objects that exist in an external world. Indeed, if all our knowledge about the world came from our sensations, and if sensations were just passive modifications of our minds, how could we infer the existence of an external world? For Condillac, our exploratory movements allow us to extract the spatial organisation of our sensations; and it is the spatial existence of the objects in the world that allows us to consider them as external. In other words, spatialisation and objecthood emerge simultaneously.

The third result of our experiments is that the notions of space and object are significantly reinforced after the participant experiences the possibility of interrupting the link between himself and the object. Thus, the possibility of obstructing perception favors the constitution of a perceptual space containing objects situated at a distance in front of the perceiver, that is the constitution of complete spatial perception. 
However, the possibility of manipulating a perceptive obstacle had no influence when participants directly held the luminous object (condition 4). In this condition, the extracted index measuring the components "space" and "object" are the same independently of whether the participant has the possibility of interrupting stimulation from the source using the cardboard sheet. We can envisage that participants effected a direct transfer between the known position of the hand to the luminous object it held. The obstacle has no influence because the participants have already identified the origin of the stimulation as being in their own hand. This condition shows that if the participant knows the position of the object, he can easily deduce the causal link between his sensations and their source.

On the other hand, in condition 2 (distant object), we assumed no help was provided to participants in making distal attribution, since there was no direct or indirect tactile access to the object or spatial landmarks. In this condition, the degree to which the component "coupling" was extracted was similar whether or not the participants had the ability to interrupt the stimulation with a sheet of cardboard. But the components "space" and "object" are reinforced after the participant experiences the possibility to interrupt the link between himself and the object. Correspondingly, the scenario corresponding to the real experimental setup appeared at the third place before use of the cardboard and was rated best after its use. What is the meaning of this progression? Participants in the "distant object" condition inferred the existence of a coupling from the first session. During the second session, the possibility of manipulating an obstacle allows a spatial comprehension of the stimulation. If the cardboard forms a screen between the subject and the stimulation, a gap between them can be inferred. In other words, the obstruction of perception allows a distance between the perceiver and the object to be perceived. Thanks to the cardboard and the possibility offered 
to temporarily isolate the stimulation, participants can dissociate an object, source of sensations, and the movements allowing variations of those sensations. Through their interactions they can discover the difference between the perceptive device they are fitted with and the object perceived through the device. Participants are then able to attribute a distant origin to their sensations and are able to understand that their actions allow a spatial displacement in front of this distant source. Indeed, through manipulation of an obstacle, participants can understand the functioning of the perceptual device they are fitted with and attribute a better score to the scenario describing the visual-to-auditory substitution device.

Our results support the hypothesis that the extraction of a correlation between selfmovements and resulting stimulation is a necessary condition for the acquisition of the concepts of space and object. This tends to confirm the hypothesis that the objects of our perception are not constituted by the invariants of sensations, but rather by the invariants linking a subject's activity to the resulting stimulation. However, this is not a sufficient condition: the correct inference of this coupling does not, in itself, lead immediately to the notion of space and object. We can understand why space and object cannot be reduced to a coupling. Even if a correlation can be extracted between action and sensation, the understanding of this coupling is different from the understanding of a displacement relative to an object. Indeed, understanding a correlation between self-movements and resulting stimulation is a comprehension that different actions gives rise to different sensations. This link between action and sensation is insufficient to reach the notion of space. There is a space of displacements when the same actions can give rise to different sensations, and when different actions can give rise to the same sensation, which then can be named "position" of an object. 
The manipulation of an obstacle allows the participants to escape from the strict correspondence between action and sensations. Now, different actions can give rise to the same sensation (or the same absence of sensation). There is dissociation between an object, source of sensations, and the movements allowing variations of those sensations. The active and reversible obstruction of perception can thus be understood as an interposition. This obstacle allowed participants to differentiate between the sensory stimulation (proximal stimulation) and the distant source giving rise to that stimulation (distal perception). The source of the stimulation can be understood as being distant because something can be interposed between the perceiver and it. Thanks to the additional sensory motor laws allowed by the reversible obstruction of perception users can understand the variations of stimulation as linked to variations of their points of view on an object situated in the distal perceptual space. They are then able to attain complete distal attribution and to identify the scenario corresponding to the real experimental setup.

In conclusion, sensory substitution devices, like all technical devices, offer to their users new spaces of action and perception. The study of the different ways of interacting with a new technical device allows an investigation of the fundamental mechanisms of perceptual activity and opens a new field of research in epistemology of perception. Indeed, understanding the mechanisms that allow the acquisition of a new tool implies the comprehension of the new spaces of action and of perception offered by the tool. It addresses the question of how users constitute new objects, new points of view and new ways to perceive and to modify their environment. Sensory substitution devices are of interest to study the learning of new spaces of action and perception. These devices can be considered at the same time as new sensory 
modalities and as new tools. They thus allow us to envisage the hypothesis that mediated perception (with a tool) and unmediated perception (with a sensory organ) follow similar mechanisms of appropriation. Studying the use of sensory substitution devices thus allows the understanding of the different components of the constitution of new perceptual spaces. In our experiments, as in Epstein and al.'s, participants easily inferred the existence of a sensorimotor coupling. We showed that the ability to infer the notions of space and objects depend on the possibility of manipulating an object or on the possibility of manipulating an obstacle between the object and the perceiver. These additional sensorimotor conditions allow the participants to build up a distal perceptual space, distal objects and perception of the real world outside, via the device.

\section{Acknowledgements}

We are grateful to Laurent Chavinier and Clément Pimor for their assistance in running participants for this experiment. We also thank Laurent Savin and Guido for their technical help on the design of the experimental material.

\section{References}

[1] Bach-y-Rita P, Brain Mechanisms in Sensory Substitution , Academic Press, New York, 1972.

[2] Bach-y-Rita P, Emerging concepts of brain function, J Integr Neurosci 4 :183-205, 2005.

[3] Bach-y-Rita P, Collins CC, Saunders FA, White B, Scadden L, Vision substitution by tactile image projection, Nature 221 :963-964, 1969.

[4] Bach-y-Rita P, Kercel SW, Sensory substitution and the human-machine interface, Trends Cogn Sci 7 :541-546, 2003.

[5] Brooks R, Cambrian Intelligence. The Early History of the New AI , MIT Press, Cambridge MA, 1999.

[6] Condillac EB, Traité des sensations , 1754, reissued in the series Corpus des oeuvres de philosophie en langue française, Fayard, Paris, 1984. 
Reprint of the submitted version of Auvray M, Hanneton S, Lenay C, O'Regan K. There is something out there: Distal attribution in sensory substitution, twenty years later. J Integr Neurosci. 2005 Dec;4(4):505-21.

[7] Epstein W, Hugues B, Schneider S, Bach-y-Rita P, Is there anything out there? A study of distal attribution in response to vibrotactile stimulation, Perception $15: 275-284,1986$. [8] Gibson JJ, The Senses Considered as Perceptual Systems, Houghton Mifflin, Boston, 1966.

[9] Gibson J], The Ecological Approach to Visual Perception , Houghton Mifflin, Boston, 1979.

[10] Helmholtz H, Physiological Optics, Optical Society of America, Rochester NY, 1909. [11] Meijer PBL, An experimental system for auditory image representations, IEEE T Biomed Eng $39: 112-121,1992$.

[12] O’Regan JK, NoÂ“e A, A sensorimotor account of vision and visual consciousness, Behav Brain Sci 24 :939-973, 2001.

[13] Piaget J, La Naissance de l'intelligence chez l'enfant, Delachaux et Niestlé, Neuchâtel,1936.

[14] Piaget J, La Construction du Réel chez l'enfant, Delachaux et Niestlé, Neuchatel, 1937.

[15] Varela FJ, Thompson E, Rosch E, The Embodied Mind: Cognitive Science and Human Experience, MIT Press, Cambridge MA, 1991.

[16] White BW, Saunders FA, Scadden L, Bach-y-Rita P, Collins CC, Seeing with the skin, Percept Psychophys 7 :23-27, 1970. 


\section{Appendix 1}

\section{Scenarios adapted for the experimental condition "distant object"}

1- A luminous object is placed on a table in front of me. An optical device located on my head films this luminous object and converts images of this object into a pattern of sounds.

2- Sensors located on my head record movements of my head. These movements create displacements of myself in front of an object in virtual reality. Images of this object are converted into pattern of sounds.

3- Movements of my head control the sounds of a musical instrument.

4- Sensors located on my head record movements of my head. Positions of my head are directly converted into a pattern of sounds.

5- The experimenter controls sound variations as a function of the movements of my head.

6- An object situated in front of me emits sounds that are not linked to my own movements. These sounds are transmitted to my ears.

7- The device is pre-programmed via a computer to produce sounds randomly, not linked to the position of my body or to my movements.

\section{Scenarios adapted for the experimental condition "object"}

1- I hold a luminous object. An optical device located on my head films this luminous object and converts images of this object into a pattern of sounds.

2- Sensors located on my head and on a luminous object that I manipulate record movements of my head and my hand. These movements create displacements in front of an object in virtual reality. Images of this object are converted into pattern of sounds.

3- Movements of my head and my hand control the sounds of a musical instrument. 
4- Sensors located on my head and on an object that I manipulate record movements of my head and my hand. Positions of my head and my hand are directly converted into a pattern of sounds.

5- The experimenter controls sound variations as a function of the movements of my head and my hand.

6- An object situated in front of me emits sounds that are not linked to my own movements. These sounds are transmitted to my ears.

7- The device is pre-programmed via a computer to produce sounds randomly, not linked to the position of my body or to my movements. 